\title{
РАСПРОСТРАНЕННОСТЬ БРОНХИАЛЬНОЙ АСТМЫ СРЕДИ ПОДРОСТКОВ В ЗАВИСИМОСТИ ОТ КЛИМАТИЧЕСКИХ ЗОН В РЕСПУБЛИКЕ ДАГЕСТАН
}

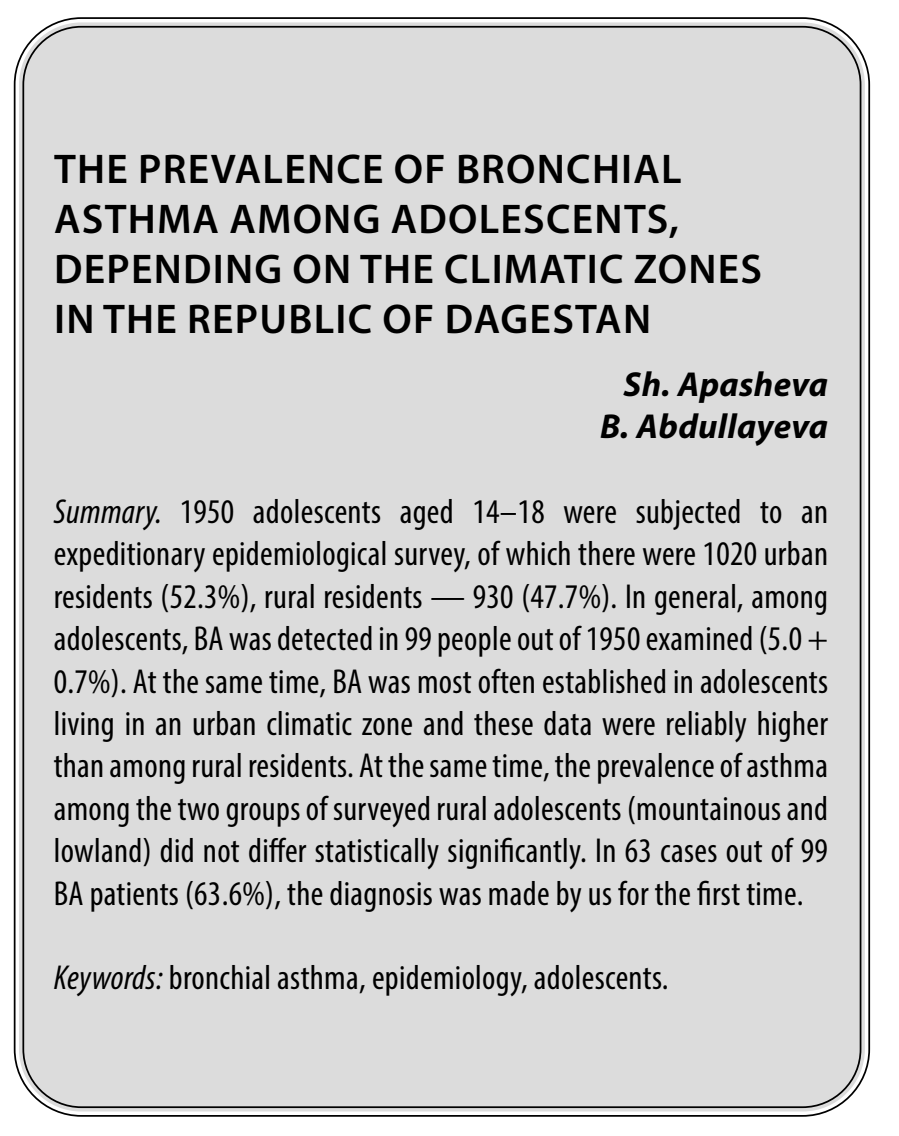

$\mathbf{K}$ ак было отмечено в литературе из разных источников, среди детского населения отмечается значительная распространенность БА по разным регионам РФ. Распространенность БА среди детей в отдельных регионах достигает 10\%, а по прогнозам, в ближайшие годы эта цифра поднимется до 20\%. [1,2,3,8]

Несмотря на то, что в последние годы особое внимание уделяется изучению распространенности БА у подростков, в регионе Северного Кавказа и в частности, в Дагестане такие исследования не проводились. Наши исследования в этом направлении будут изложены ниже.

\section{Цель исслеАования}

Изучить распространенность бронхиальной астмы у подростков в зависимости от факторов экосистемы и климатических зон в республике Дагестан.

\author{
Апашева Шуанат Ахмеднабиевна \\ К.м.н., дочент, ФГБОУ ВО "Дагестанский \\ государственный медицинский университет" \\ Минздрава России \\ shuanadoctor@mail.ru \\ Абдуллаева Барият Сайпулаевна \\ Ассистент, ФГБОУ ВО "Дагестанский \\ государственный медицинский университет" \\ Минздрава России
}

Аннотация. Экспедиционному эпидемиологическому обследованию подвергнуто 1950 подростков в возрасте 14-18 лет, из которых городских жителей было 1020 (52,3\%), сельских жителей-930 (47,7\%). В целом среди подростков БА выявлена у 99 человек из 1950 обследованных (5,0+0,7\%). При этом БА наиболее часто установлена у подростков, проживающих, В городской климатической зоне и данные эти достоверно были выше чем среди жителей сельской местности. В тоже время распространенность БА среди двух групп обследованных сельских подростков (горная и равнинная) статистически значимо не отличалась. В 63 случаях из 99 больных БА (63,6\%) диагноз был выставлен нами впервые.

Ключевые слова: бронхиальная астма, эпидемиология, подростки.

\section{Материа^ и метонь исслеАОвания}

Экспедиционному эпидемиологическому обследованию подвергнуто 1950 подростков в возрасте 14-18 лет, из которых городских жителей было 1020 (52,3\%), сельских-930 (47,7\%), в том числе 629 жители горной местности и 301-равнинной. Средний возраст составил 15,9+0,8 лет. Среди подростков девочек было 1025 (52,5\%), мальчиков-925 (47,5\%).

На первом этапе нами была использована методика эпидемиологического обследования с помощью анкеты-опросника Европейского респираторного общества (ECRHS). На втором этапе группа подростков прошла клиническое обследование с изучением физикальных данных, определением бронхиальной проходимости по данным спирометрии и пикфлуометрии, определением иммуноглобулина $\mathrm{G}$ и эозинофилов в крови. Изу- 
Таблица 1. Распространенность БА среди подростков по данным обращаемости (на 1000) в зависимости от климатических зон за 5 лет (2015-2019гг)

\begin{tabular}{|l|l|l|l|l|l|}
\hline \multirow{2}{*}{ Климатическая зона } & Годы & $\mathbf{2 0 1 6}$ & $\mathbf{2 0 1 7}$ & $\mathbf{2 0 1 8}$ & $\mathbf{2 0 1 9}$ \\
\cline { 2 - 6 } & $\mathbf{2 0 1 5}$ & 0,58 & 0,56 & 1,04 & 0,87 \\
\hline Горы & 0,68 & 0,33 & 0,76 & 1,50 & 2,10 \\
\hline Предгорье & 0,41 & 0,51 & 1,09 & 1,30 & 2,20 \\
\hline Равнина & 0,69 & &
\end{tabular}

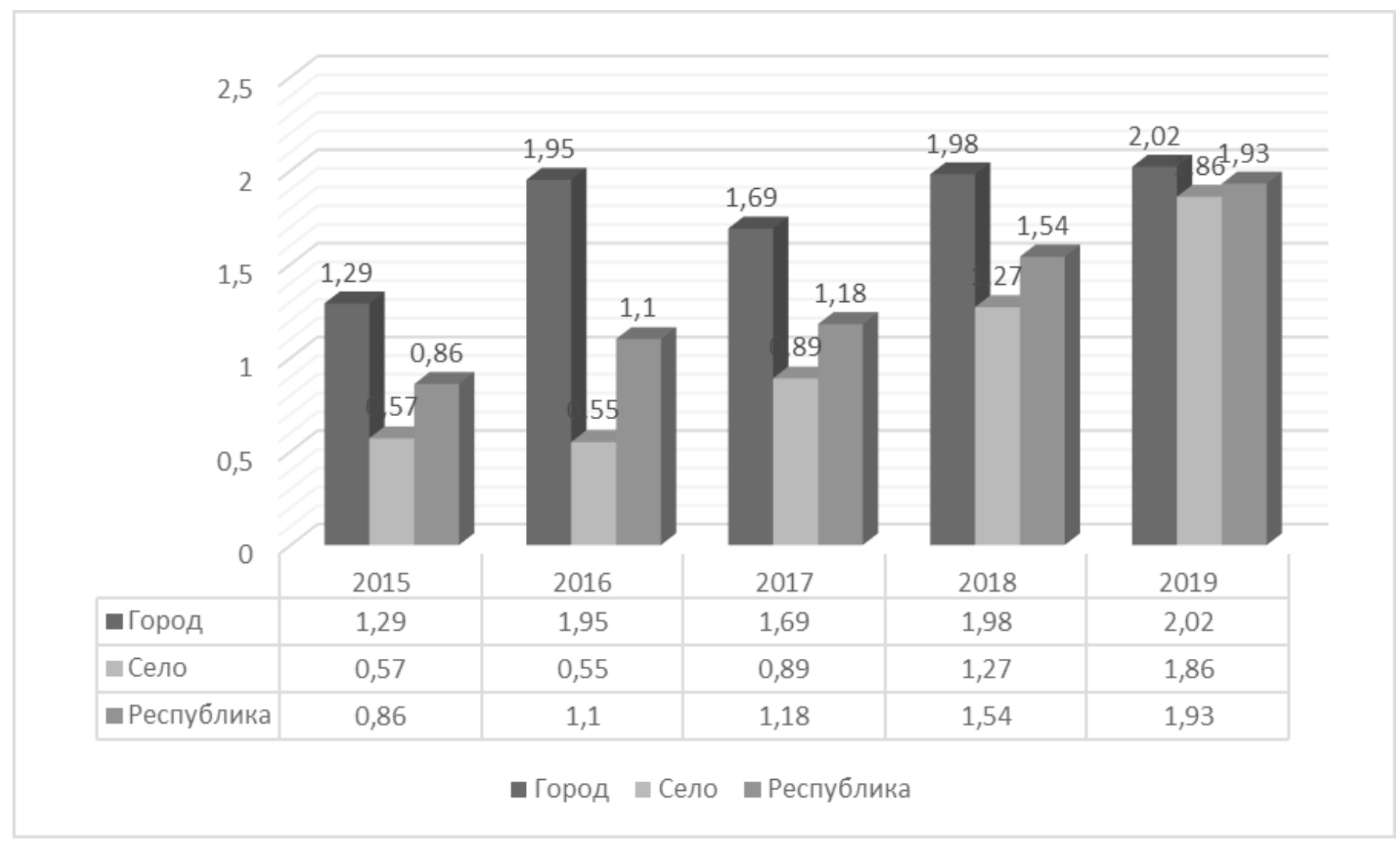

Рис 1. Динамика заболеваемости БА у подростков Дагестана по годам в городской и сельской местности, по данным обращаемости (на 1000 населения).

чены данные по заболеваемости и болезненности среди подростков в РД за 5 лет (2015-2019гг).

\section{Результаты исслеАования}

Заболеваемость БА среди подростков, по данным обращаемости, была проанализированы за 5 лет (20152019 гг), и эти данные представлены на рис. 1.

Из этих данных видно, что, во-первых, в целом по республике прирост обращаемости по поводу БА у подростков составил 124,4\% (с 0,86 до 1,93 на 1000 население); во-вторых, неуклонный рост заболеваемости БА наблюдается в сельской местности (228\% против
53,8\% в городах), в-третьих, свои особенности заболеваемость имеет в зависимости от высоты проживания над уровнем моря (горы - более 1000 м, предгорье -500-1000 м, равнина - менее 500 м). (см. таблицу 1).

При сравнительной оценке данных распространенности БА в г/м и с/м выявлены следующие закономерности: в целом в с/м почти в 2 раза реже подростки страдают БА, чем в городе (сводные цифры за 5 лет на 1000 населения - в с/м - 0,96, в г/м - 1,78). Хотя прирост числа больных БА подростков отмечен и среди жителей городов (на 53,8\%), но среди сельских подростков прирост за 5 лет превысил в 4 раза и составил $228 \%$ (0,57 в 1999 г. и 1,86 в 2003 г.). 
Таблица 2. Распределение больных БА у подростков в зависимости от тяжести течения по климатических зонам (абс. число и\% к количеству исследованных)

\begin{tabular}{|l|l|l|l|l|}
\hline $\begin{array}{l}\text { Клиническая } \\
\text { Форма БА }\end{array}$ & $\begin{array}{l}\text { Жители гор } \\
(\mathbf{n = 6 2 9 )}\end{array}$ & $\begin{array}{l}\text { Сельские жители } \\
\text { приморье } \\
\text { (n=301) }\end{array}$ & $\begin{array}{l}\text { Городские } \\
\text { жители } \\
(\mathbf{n = 1 0 2 0 )}\end{array}$ & $\begin{array}{l}\text { Bceго } \\
(\mathbf{n}=1950)\end{array}$ \\
\hline Латентная & $10(1,55)^{*}$ & $4(1,3)^{*}$ & $49(4,8)$ & $63(3,2)$ \\
\hline Интермитирующая & $1(0,15)$ & $2(0,66)$ & $11(1,07)$ & $14(0,72)$ \\
\hline Персистирующая легкая & $1(0,15)$ & $2(0,66)^{* *}$ & $7(0,69)$ & $10(0,51)$ \\
\hline Средней тяжести & $1(0,15)$ & $2(0,66)$ & $4(0,39)$ & $7(0,35)$ \\
\hline Тяжелая & - & $1(0,33)$ & $4(0,39)$ & $5(0,25)$ \\
\hline Итого & $13(2,07)^{*}$ & $11(3,6)^{*}$ & $75(7,4)$ & $99(5,0)$ \\
\hline
\end{tabular}

*-разница достоверна между городом и селом (горы)

** между селами в горной и приморской зоне

Таблица 3. Распространенность БА среди подростков в зависимости от пола (\%).

\begin{tabular}{|l|l|l|l|}
\hline Диагноз & Мальчики $\mathbf{n = 9 2 5}$ & Девочки $\mathbf{n = 1 0 2 5}$ & $\mathbf{P}$ \\
\hline БА БА & $4,4+0,8$ & $5,6+0,7$ & $>0,05$ \\
\hline
\end{tabular}

Наиболее ощутимый рост заболеваемости БА отмечен в предгорной климатической зоне. В 2015 году в этой зоне показатель на 1000 населения составил 0,41, а в 2019 г. он вырос до 2,1 (увеличение в 5,1 раз). Почти такая же картина наблюдалась в равнинной климатической зоне. В 2015 году показатель равнялся 0,69, а в 2019 г.- 2,2 (увеличение в 3,2 раза).

Общеизвестно, что начальные формы БА не всегда принимаются как астма, имеются варианты нетипичного течения и для выяснения истинной картины распространенности необходимо проведение экспедиционных эпидемиологических исследований в популяции.

С этой целью нами были проведены эпидемиологические исследования в 3 школах г. Махачкалы расположенных в различных районах города с разной экологической загруженностью территории и среди подростков, проживающих в с/м. Кроме того, была дана подробная оценка клинико-функциональным показателям у 63 больных БА подростков, впервые обратившихся за медицинской помощью или выявленных при эпидемиологическом обследовании.

Обследованию подвергнуто 1950 детей - школьников в возрасте 14-18 лет. Мужской пол - 925 (47,4\%), женский -1025 (52,6\%) человек.

Данные о распространенности БА среди подростков республики Дагестан в зависимости от климатических зон представлены в таблице 2.
В целом среди подростков РД БА выявлена у 99 человек из 1950 обследованных (5,0+0,7\%). При этом БА наиболее часто установлена у подростков, проживающих, в городской климатической зоне и данные эти достоверно были выше чем среди жителей сельской местности (7,4\% против данных в сельской местности в горной зоне $-2,0 \%$ : $p<0.01)$. В тоже время распространенность БА среди двух групп обследованных сельских подростков (горная и равнинная) статистически значимо не отличалась, хотя в равнинной зоне установлена несколько чаще. В 63 случаях из 99 больных БА (63,6\%) диагноз был выставлен нами впервые, а участковые педиатры, как правило, этих подростков вели под диагнозами хронический бронхит, острая пневмония или респираторная инфекция и назначали безуспешно антибактериальные препараты. [6,9]

Как видно из таблицы 2 у больных установленной БА (с типичными приступами удушья в анамнезе) заболевание по тяжести течения распределялось следующим образом: интермитирующее течение имели 14 из 36 больных (38,8\%), легкое персистирующее течение - 10 из 36 (27,7\%), средней тяжести течения - 7 (19,4\%), тяжелое течение -5 (13,8\%).

В горной климатической зоне симптомы БА были стерты, проявлялись периодическим посвистыванием, общей слабостью, быстрой утомляемостью, одышкой при физической нагрузке или эпизодическим кашлем, который, как правило, исчезал самостоятельно. Иногда заболевание сопровождалось кратковременной лихо- 
Таблица 4. Частота респираторной симптоматики в зависимости от пола у подростков, проживающих в г/м (абс. число и $\mathrm{M}+\mathrm{m} \%)$.

\begin{tabular}{|c|c|c|c|}
\hline \multirow{2}{*}{ Симптомы } & \multicolumn{2}{|l|}{ Пол } & \multirow{2}{*}{ Всего $n=1020$} \\
\hline & $M n=460$ & $\nVdash n=560$ & \\
\hline Кашель & $90(19,5+1,8)$ & $100(17,8+1,6)$ & $190(18,6+1,2)$ \\
\hline $\begin{array}{l}\text { Ночной } \\
\text { приступообразный кашель }\end{array}$ & $57(12,3+1,5)$ & $70(12,5+1,4)$ & $127(12,4+1,0)$ \\
\hline Мокрота & $118(25,6+1,9)$ & $192(34,2+2,0)$ & $310(30,4+1,4)$ \\
\hline Одышка при физической нагрузке & $94(20,4+1,8)$ & $198(35,3+2,1)$ & $292(28,6+1,4)$ \\
\hline Одышка периодичес-кая приступообразная & $35(7,6+1,2)$ & $30(5,3+1,9)$ & $65(6,4+1,6)$ \\
\hline Сухие хрипы & $43(9,3+1,3)$ & $28(5,0+0,9)$ & $71(6,9+0,8)$ \\
\hline «Частые простуды» в анамнезе & $137(29,8+2,1)$ & $218(38,9+2,1)$ & $355(34,8+3,1)$ \\
\hline $\begin{array}{l}\text { ПФМ ниже 80\% } \\
\text { от должной }\end{array}$ & $38(8,2+1,2)$ & $52(9,3+1,2)$ & $90(8,8+0,9)$ \\
\hline
\end{tabular}

Таблица 5. Показатели бронхиальной проходимости (по данным ПФМ) у подростков, полученных на первом этапе обследования (М+m\%)

\begin{tabular}{|l|l|}
\hline Группы исследованных & ПФМ в\% к должной \\
\hline $\begin{array}{l}\text { Здоровые лица } \\
(П=74)\end{array}$ & $99,8+1,5$ \\
\hline БА латентная (п=63) & $97,2+1,7$ \\
\hline БА установленная (п=36) & $95,4+2,0^{*}$ \\
\hline
\end{tabular}

*-р<0,05 разница между больными и здоровыми лицами

радкой, кашлем, что служило основанием диагностической ошибки и неэффективного лечения (см.случай и рис. 3.2.)

Заметная разница в распространенности БА в зависимости от пола нами не установлена, что представлено в таблице 3.

БА с одинаковой частотой наблюдались как у девочек, так и у мальчиков. Несмотря на то, что цифры распространенности БА у девочек также были несколько выше, но они статистически достоверно не отличались ( $>$ >005). БА диагностирована у девочек в 5,6\% случаев, а у мальчиков - в 4,4\%.

В целом в группе обследованных респираторная симптоматика (кашель, мокрота, частые простуды, одышка и т.д.) выявлена в достаточно высоком проценте случаев, что видно из таблицы 3.4.

Интерес представляет то, что 127 человек жителей города $(12,4 \%)$ жаловались на периодический ночной приступообразный кашель, который считается более характерным для больных БА, периодическая приступообразная одышка и посвистывание в груди зарегистрировано в 65 случаях (6,4\%). Показатель ПФМ ниже $80 \%$ зарегистрирован у 90 человека (8,8\%). Какой-либо достоверной разницы в частоте респираторной симптоматики по половому признаку нами не отмечено, несмотря на то, что «частые простуды», одышка при физической нагрузке и мокрота несколько чаще наблюдались у девочек.

При этом, что очень важно, из 99 больных БА, выявленных нами на первом этапе эпидемиологического обследования, врачами диагноз был установлен всего у 36 человек (36,4\%). В 63,6\% случаев диагноз БА выставлен нами впервые. Специального пульмонологического, аллергологического обследования этим больным на амбулаторном этапе не проводилось

Анализ показателей ПФМ, полученных на первом этапе обследования показал, что у больных с латентной БА этот показатель $(97,2+1,7 \%)$ существенно не отличался по сравнению со здоровыми лицами (99,8+1,5\%). Только у больных БА установленной наблюдалось статистически достоверное снижение ПФМ (95,4+2,0\%) по сравнению со здоровой группой $(p<0,05)$.

В 22 случаях из 86 больных БА подростков показатели БП оказались не измененными и только в 4 случаях $(4,7 \%)$ они носили значительный характер. У остальных исследованных изменения бронхиальной проходимости носили легкий $(32,6 \%)$ и умеренный $(37,1 \%)$ характер 
Таблица 6. Степень нарушения бронхиальной проходимости у больных БА подростков в\%.

(по данным спирометрии).

\begin{tabular}{|l|l|l|}
\hline Степень нарушения БП & Количество больных & Процент \\
\hline Норма & 22 & 25,6 \\
\hline Легкие & 28 & 32,6 \\
\hline Умеренные & 32 & 37,1 \\
\hline Значительные & 4 & 4,7 \\
\hline Всего & 86 & 100 \\
\hline
\end{tabular}

Таблица 7. Содержание общего IgЕ в крови, абсолютного количества эозинофилов в крови у здоровых и больных БА подростков.

\begin{tabular}{|l|l|l|}
\hline Показатель & 3доровые =21 & Больные БА =29 \\
\hline Уровень IgЕ в крови в МЕ/мл & $52,2+4,2$ & $159,7+16,6^{*}$ \\
\hline Абс. кол. Эозинофилов в х10\%/л & $0,180+0,03$ & $0,286+0,05^{*}$ \\
\hline Процент эозинофилов в крови & $2,2+0,3$ & $5,06+0,6^{*}$ \\
\hline
\end{tabular}

* разница значима между здоровыми и больными подростками

Основными клиническими симптомами были следующие признаки: периодический приступообразный ночной кашель, изнурительный, малопродуктивный, который завершался приступом одышки, у 63 из 86 больных (73,3\%), типичные приступы БА, хорошо купирующиеся бета-2 агонистами или эуфиллином у 11 человек (12,8\%), сухие хрипы в легких при аускультации -у 43 больных (50\%). [5, 14]

68 из 86 больных (79\%), указывали на выделение мокроты, чаще в небольшом количестве, пенистого характера, а в 34 (50\%) случаев из них при исследовании найдены эозинофилы от 2 до 15\% в клеточном составе. Процентное содержание эозинофилов в крови оказалось существенно выше, чем у здоровых подростков $(5,06+0,6 \%$ против $2,2+0,3 \%$ у здоровых, $p<0,05)$. Абсолютное количество эозинофилов в периферической крови у больных БА также оказалось значительно больше, чем у здоровых подростков. Так в 71,4\% случаев этот показатель был выше, чем в контрольной группе $(180+3,0$ × 10\%). Средние цифры абсолютного количества эозинофилов у больных БА составили 286+5,1×10\%/л. Разница статистически достоверна $(\mathrm{p}<0,01)$.

У 10 из 16 (62,5\%) больных БА (табл. 3.7) содержание общего IgЕ оказалось больше предельно допустимой концентрации (120 ME/мл) и колебалось в пределах от 126 до $356 \mathrm{ME} / \mathrm{мл}$.

Среднее его содержание у больных составило 159,7+16,6 MЕ/мл, тогда как у здоровых подростков оно ровнялось 56,2+4,2 МЕ/мл. Разница статистически значима $(p<0,001)$.

\section{Выво $\Delta \mathrm{b}$}

1. Бронхиальная астма - распространенное заболевание у подростков в Дагестане, которое встречается в выборке в 5,0\% случаев. Имеется стойкая тенденция к ежегодному приросту ее частоты и тесная зависимость, как от климатических зон, так и факторов экосистемы. [11,12]

2. При этом БА наиболее часто установлена у подростков, проживающих, в городской климатической зоне и данные эти достоверно были выше чем среди жителей сельской местности $(7,4 \%$ против данных в сельской местности в горной зоне $-2,0 \%$ : $p<0.01)$. В тоже время распространенность БА среди двух групп обследованных сельских подростков (горная и равнинная) статистически значимо не отличалась, хотя в равнинной зоне установлена несколько чаще.

3. БА с одинаковой частотой наблюдались как у девочек, так и у мальчиков. Несмотря на то, что цифры распространенности БА у девочек также были несколько выше, но они статистически достоверно не отличались ( $>>005)$. БА диагностирована у девочек в 5,6\% случаев, а у мальчиков - в 4,4\% [10]

4. При сравнительной оценке данных распространенности БА в г/м и с/м выявлены следующие закономерности: в целом в с/м почти в 2 раза реже подростки страдают БА, чем в городе (сводные цифры за 5 лет на 1000 населения - В с/м - 0,96, в г/м - 1,78). Хотя прирост числа больных БА подростков отмечен и среди жителей городов (на 53,8\%), но среди сельских подростков при- 
рост за 5 лет превысил в 4 раза и составил $228 \%$ (0,57 в 1999 г. и 1,86 в 2003 г.).

5. В 63 случаях из 99 больных БА (63,6\%) диагноз был выставлен нами впервые, а участковые пе- диатры, как правило, этих подростков вели под диагнозами хронический бронхит, острая пневмония или респираторная инфекция и назначали безуспешно антибактериальные препараты.

\section{ЛИТЕРАТУРА}

1. Заболотских Т.В., Баранзаева Д.Ч., Григоренко Г.В. Распространенность БА у школьников г. Благовещенко. //Сб. Резюме. 12 Нац. конгр. по болезням органов дыхания -М.-2002.-С 398 .

2. Батожаргалова Б.Ц., Мизерницкий Ю.Л. Бронхиальная астма у подростков в сельской местности Забайкальского края: динамика распространенности и гендерные различия. Тихоокеанский медицинский журнал. 2011;(2):66-68.

3. Намазова-Баранова Л.С., Огородова Л.М., Томилова А.Ю., Деев И.А., Алексеева А.А., Вишнева Е.А., Громов И.А., Евдокимова Т.А., Камалтынова Е.М., Коломеец И.Л. ТРМ. Распространенность астмаподобных симптомов и диагностированной астмы в популяции подростков. Педиатрическая фармакология. 2009;6(3):59-55.

4. Аллергология и иммунология / Союз педиатров России. - 3-е изд., испр. и доп. - М.: Союз педиатров России, 2011. - 256 с.

5. Вишнёва Е.А., Намазова-Баранова Л.С., Алексеева А.А., Эфендиева К.Е., Левина Ю.Г., Вознесенская Н.И., Томилова А.Ю., Селимзянова Л.Р. ПЕА. Детская астма: ключевые принципы достижения контроля на современном этапе. Педиатрическая фармакология. 2013;10(4):60-72.

6. Оказание стационарной помощи детям. Карманный справочник. - 2-е издание.— Женева; Всемирная организация здравоохранения, 2013.— 412 c. http://www.who.int/.

7. Блинова А.С., Почивалова В., Звягин А.А. К вопросу эпидемиологических исследований бронхиальной астмы у школьников //12 национ. Конгр. По бол. Органов дыхания М.-2002.-С.396

8. Биличенко Т.Н., Чучалин А.Г., Ефименко Н.В, и др. Загрязнение атмосферного воздуха и здоровье детей (Москва, 5-летнее исследование по программе ISAAC) //Сборн. тезисов Междунар. Конгресс по туберк. и бол. орг. дыхания и 14 Нац. конгр.по бол. орг. дых. Москва .-2004. -С.438.

9. Блинова А.С., Почивалова В., Звягин А.А. К вопросу эпидемиологических исследований бронхиальной астмы у школьников //12 национ. Конгр. По бол. Органов дыхания М.-2002.-С.396

10. Бронхиальная астма. Под ред.акад РАМН Чучалина А.Г. - М., 1997 — т. 1-2.

11. Бронхиальная астма. Глобальная стратегия. //Пульмонология. - 1996 - Приложение.

12. Голевцова 3.Ш., Багишева Н.В., Овсянников Н.В. Диагностическая ценность и информативность клинических и фенотипических признаков в ранней диагностике бронхиальной астмы. //Пульмонология 2005; № 1.-С.48-53.

13. Дрожнев И.Н., Лев Н.С., Костюченко. М.В. и соавт. Новые данные о распространенности бронхиальной астмы у детей. //Сб. Резюме. 12 Нац. Конг. По бол. Органов дыхания.- М.-2002.-С.393

14. Global Initiative for asthma. Global Strategy for Asthma Management and Prevention, 2017. Available from: www.ginasthma.org.

с Апашева Шуанат Ахмеднабиевна ( shuanadoctor@mail.ru ), Абдуллаева Барият Сайпулаевна.

Журнал «Современная наука: актуальные проблемы теории и практики» 